\title{
Unjuk Kerja Turbin Savonius Menggunakan Generator Sinkron Magnet Permanen pada Variasi Pembebanan dan Kecepatan Angin yang Berbeda
}

\author{
Yusuf Dewantoro Herlambang $^{1}$, Supriyo ${ }^{2 *}$, Budi Prasetiyo ${ }^{1}$, Teguh Harijono Mulud ${ }^{1}$ \\ ${ }^{1}$ Teknik Konversi Energi, Jurusan Teknik Mesin, Politeknik Negeri Semarang \\ ${ }^{2}$ Teknologi Rekayasa Pembangkit Energi, Jurusan Teknik Mesin, Politeknik Negeri Semarang \\ Jl. Prof. H. Soedarto, S.H. Tembalang, Semarang, 50275 \\ *E-mail: supriyo.mesin@polines.ac.id
}

Diterima: 14-07-2021; Direvisi: 26-07-2021; Dipublikasi: 27-08-2021

\begin{abstract}
Abstrak
Energi angin merupakan sumber energi terbarukan yang sangat melimpah di Indonesia, karena merupakan negara tropis yang memiliki potensi angin yang cukup besar. Penelitian ini difokuskan pada turbin angin Savonius poros vertikal karena mampu menerima aliran angin dari segala arah. Tujuan penelitian ini adalah membuat turbin Savonius putaran rendah menggunakan generator sinkron permanen magnet untuk meningkatkan kinerja pada kondisi kecepatan angin yang berbeda. Metode penelitian ini adalah merancang, membuat, menguji alat, dan menganalisis kinerja turbin Savonius pada kecepatan angin $5 \mathrm{~m} / \mathrm{s}, 7 \mathrm{~m} / \mathrm{s}, 9 \mathrm{~m} / \mathrm{s}$, dan $11 \mathrm{~m} / \mathrm{s}$. Turbin Savonius ini memiliki dimensi rangka sudu tinggi $700 \mathrm{~mm}$ dan dimensi sudu turbin tinggi $800 \mathrm{~mm}$, lebar diameter sudu $680 \mathrm{~mm}$. Mekanisme transmisi menggunakan v-belt dan pulley berdiameter $60 \mathrm{~mm}$ dan $120 \mathrm{~mm}$ yang dihubungkan dengan generator sinkron magnet permanen, Sedangkan tinggi rangka penyangga $750 \mathrm{~mm}$ dilengkapi denga roda jalan. Hasil penelitian menunjukkan bahwa pada pembebanan $5 \mathrm{~W}$ menghasilka putaran generator rata-rata $520 \mathrm{rpm}$ dan daya generator sebesar 5,29 W.
\end{abstract}

Kata kunci: Unjuk kerja; turbin Savonius; daya generator; generator magnet permanen; pembebanan

\begin{abstract}
Wind energy is a renewable energy source that is very abundant in Indonesia, because it is a tropical country that has a large enough wind potential. This research is focused on the vertical axis Savonius wind turbine because it is able to receive wind flow from all directions. The purpose of this research is to make a low-speed Savonius turbine using a permanent magnet synchronous generator to improve performance at different wind speed conditions. The research method is to design, manufacture, test tools, and analyze the performance of the Savonius turbine at wind speeds of 5 $\mathrm{m} / \mathrm{s}, 7 \mathrm{~m} / \mathrm{s}, 9 \mathrm{~m} / \mathrm{s}, 11 \mathrm{~m} / \mathrm{s}$, and $13 \mathrm{~m} / \mathrm{s}$. Savonius turbine has a high blade frame dimension of $700 \mathrm{~mm}$ and a turbine blade dimension of $800 \mathrm{~mm}$ high, the blade diameter width is $680 \mathrm{~mm}$. The transmission mechanism uses a v-belt and pulley with a diameter of $60 \mathrm{~mm}$ and $120 \mathrm{~mm}$ which is connected to a permanent magnet synchronous generator, while the height of the $750 \mathrm{~mm}$ support frame is equipped with road wheels. The results showed that the $5 \mathrm{~W}$ loading resulted in an average generator rotation of $520 \mathrm{rpm}$ and a generator power of $5.29 \mathrm{~W}$.
\end{abstract}

Keywords: Performance; Savonius turbine; generator power; magnet permanent generator; load

\section{Pendahuluan}

Semakin menipisnya sumber energi yang tidak terbarukan (non-renewable), serta penggunaan bahan bakar yang ramah lingkungan, memerlukan suatu jalan alternatif guna mengganti sumber energi yang tidak terbarukan diungkapkan oleh Akwa dkk. [1], Herlambang dkk. [2]. Indonesia memiliki potensi energi angin yang sangat besar yaitu sekitar 9,3 GW dan total kapasitas yang baru terpasang saat ini sekitar 0,5 MW Jika tidak ditemukan alternatif energi baru, maka akan terjadi krisis energi seperti yang dijelaskan Herlambang dkk. [3], Ali [4], Herlambang dkk. [5]. Beberapa tempat di Indonesia sudah mengalami krisis energi, sehingga pemadaman listrik sering terjadi khususnya di luar pulau Jawa, seperti Sumatera, Kalimantan dan Papua. Permasalahan tersebut dapat diatasi dengan solusi yaitu menemukan sumber-sumber energi baru yang ramah lingkungan disampaikan oleh Herlambang dkk. [6,7]. Energi angin merupakan energi yang ramah lingkungan dan bersifat renewable, untuk itu sangat berpotensi untuk dikembangkan. Tetapi sebagian besar wilayah Indonesia mempunyai kecepatan angin rendah berkisar $2 \mathrm{~m} / \mathrm{s}-5 \mathrm{~m} / \mathrm{s}$. Penelitian Asy'ari dkk. [8], Damak dkk. [9] 
menyebutkan rancangan turbin angin yang sesuai untuk daerah kecepatan angin rendah bisa diaplikasikan untuk pembangkitan listrik, sehingga bisa memenuhi kebutuhan energi di masyarakat.

Turbin Savonius adalah salah satu turbin paling sederhana. Turbin ini pertama kali diusulkan oleh insinyur Sigurd Johannes Savonius pada tahun 1922. Penelitian Herlambang dkk. [10] menyatakan bahwa turbin Savonius memiliki kelebihan bisa diletakkan disegala tempat dan bisa menerima angin dari segala arah. Secara aerodinamis, Savonius adalah turbin tipe vertikal, yang terdiri dari dua atau tiga bilah. Turbin angin double blade Savonius akan terlihat seperti bentuk huruf S, seperi pada Gambar 1. Turbin angin Savonius bekerja karena perbedaan gaya yang diberikan pada setiap blade. Blade bawah (bagian cekung ke arah angin) menangkap angin udara dan memaksa blade untuk berputar di sekitar poros vertikal tengahnya. Sedangkan blade atas (bagian cembung ke arah angin) mengenai blade dan menyebabkan angin udara dibelokkan ke samping dalam penelitian Wenehenubun et al. [11].
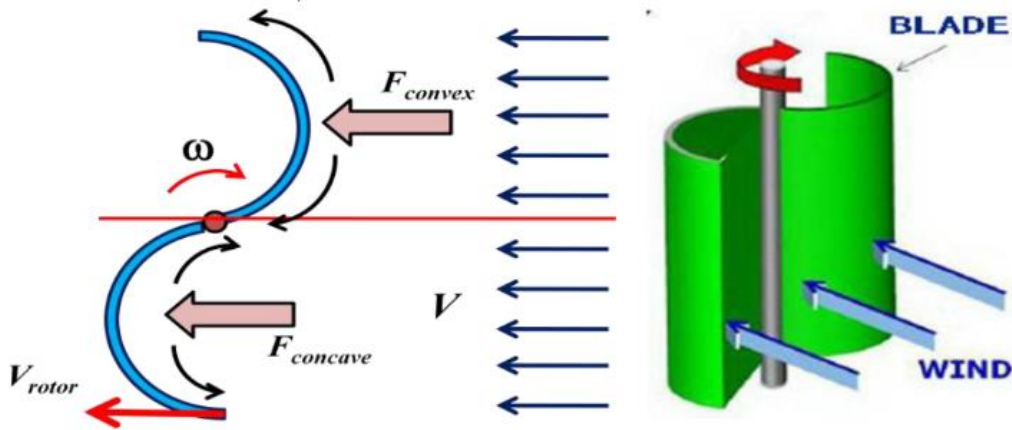

Gambar 1. Gaya geser yang diberikan pada dua blade Savonius [11]

Gesekan diferensial menyebabkan turbin Savonius berputar. Karena alasan ini, turbin Savonius mengekstraksi tenaga angin jauh lebih sedikit dari pada turbin tipe lift lain yang berukuran hampir sama karena banyak daya yang ditangkap akan hilang sebagian karena mengenai blade cembung, sehingga turbin angin Savonius memiliki efisiensi yang lebih rendah [12]. Penelitian yang dilakukan Latif [13] menggunakan bentuk rotor Savonius setengah lingkaran aliran udara di kedua sisi sudu sama besar (Savonius S), sementara pada rancangan kedua (Savonius L) aliran udara pada sisi sudu yang lurus lebih besar dibandingkan pada sisi sudu lengkung seperempat lingkaran.

State of the arts (kebaruan) dari penelitian ini adalah turbin Savonius memiliki 2 lapis sudu pada sisi tip, sehingga dengan adanya dobel kelengkungan akan menambah gaya dorong oleh bantuan angin, sedangkan pada sisi sudu yang cekung akan mengalami gaya gesek melawan angin. Oleh karena itu, blade sisi cekung menghadap angin akan mengalami gaya dorong lebih dikarenakan adanya 2-lapis sudu daripada pada sisi root sudu, sehingga memaksa rotor berputar dengan tambahan gaya dorong yang akan menaikkan torsi turbin. Dobel lapis sudu ini akan menambah ekstraksi gaya dorong yang hilang akibat adanya sisi sudu yang cembung, sehingga akan menambah efisiensi turbin.

Penelitian terkait tipe-tipe turbin angin putaran generator rendah sedang banyak dikembangkan oleh para peneliti agar mampu dan cocok diterapkan diberbagai wilayah yang memiliki potensi sebagai PLTB. Penelitian Herlambang dkk. $[14,15]$ menyatakan bahwa turbin angin jenis Savonius sumbu poros vertical bisa diterapkan dimanapun dan memiliki gaya drag yang lebih besar dibandingkan dengan gaya angkat, sehingga cocok digunakan untuk keperluan daya mekanik yang memerlukan torsi yang lebih besar. Disamping itu, turbin Savoius juga mampu menerima aliran angin dari segala arah, memiliki self-starting yang baik, sehingga mampu memutar rotor pada kecepatan angin rendah, selain itu torsi yang dihasilkan juga relatif tinggi. Turbin ini memiliki bentuk dan konstruksi yang sederhana dan disusun menyerupai huruf S. Oleh karena itu, penelitian ini dimaksudkan untuk mengetahui unjuk kerja turbin angin Savonius pada putaran rendah 
pada berbagai kecepatan angin yang mengalir sepanjang sudu terhadap aliran angin yang memberikan pengaruh terhadap kecepatan angin keluaran sudu untuk meningkatkan kinerja generator.

\section{Material dan metodologi}

Peralatan pengujian yang digunakan adalah blower, tachometer, anemometer, amperemeter, voltmeter, dan kabel spade dan kabel crocodile. Langkah Pengujian yang dilaksanakan adalah: 1). mempersiapkan semua peralatan uji yang akan digunakan baik sebagai komponen pendukung maupun alat pengukuran seperti blower, anemometer, tachometer voltmeter, amperemeter, kabel, multimeter, dan torsimeter; 2). merangkai voltmeter, amperemeter, generator dan beban menggunakan kabel spade dan kabel crocodile; 3). menyiapkan turbin single blade untuk dilakukan pengujian; meng-onkan blower; 4). mengatur jarak blower pada turbin untuk menentukan kecepatan angin yang diinginkan; 5) melakukan pengujian dengan kecepatan angin $5 \mathrm{~m} / \mathrm{s} ; 6$ ) mengukur kecepatan putaran poros turbin dan poros generator menggunakan Tachometer; 7). Mengukur besar torsi dan mencatat nilai voltmeter dan amperemeter; 8). menambah beban sebesar $5 \mathrm{~W}$ kemudian mencatat parameter yang dibutuhkan, tambah beban sebesar $5 \mathrm{~W}$ secara bertahap hingga kondisi menyala redup dan arus jenuh; 9). mengulangi langkah 6 dengan variasi kecepatan angin $7 \mathrm{~m} / \mathrm{s}, 9 \mathrm{~m} / \mathrm{s}, 11 \mathrm{~m} / \mathrm{s}, 13 \mathrm{~m} / \mathrm{s}$; 10). mengulangi langkah 3 s.d. langkah 10 untuk setiap variasi sudu; 11). mencatat hasil arus generator, tegangan generator, kecepatan putar poros turbin poros generator; 12). mematikan blower; 13). mengolah data, mencatat hasil dalam tabel, dan membentuk dalam bentuk kurva karakteristik turbin. Untuk memahami analisis kinerja turbin Savonius, maka perlu diperhatikan adalah parameter daya kinetik $\left(\mathrm{P}_{\mathrm{kin}}\right)$, gaya yang bekerja pada sudu, daya mekanik $\left(\mathrm{P}_{\mathrm{mek}}\right)$, coefficient of power (Cp), tip speed ratio (tsr), daya generator (Pg), dan efisiensi sistem.

Parameter unjuk kerja turbin angin dinyatakan oleh Herlambang dkk. [16]:

a. Daya Kinetik (Pkin), daya kinetik adalah daya angin yang diterima turbin dapat juga disebut daya input.

$$
P_{k i n}=\frac{1}{2} \rho A v^{3}
$$

dimana, $\mathrm{P}_{\text {kin }}$ adalah daya kinetik $(\mathrm{W}), \rho$ adalah densitas udara $\left(\mathrm{kg} / \mathrm{m}^{3}\right), \mathrm{A}$ adalah luas sapuan rotor $\left(\mathrm{m}^{2}\right)$, dan $\mathrm{V}$ adalah kecepatan angin $(\mathrm{m} / \mathrm{s})$.

b. Daya Mekanik (Pmek), daya mekanik adalah daya putaran poros yang dihasilkan oleh sudu turbin.

$$
P_{m e k}=\frac{2 \pi n T}{60}
$$

dimana, $\mathrm{P}_{\mathrm{mek}}$ adalah daya mekanik (W), $\mathrm{n}$ adalah putaran poros (rpm), $\mathrm{T}$ adalah torsi $(\mathrm{Nm})$.

c. Coefficient of Power $(\mathrm{Cp})$, coefficient of power atau koefisien daya merupakan perbandingan daya mekanik atau daya putaran poros dengan daya kinetik angin.

$$
C p=\frac{P_{m e k}}{P_{k i n}}
$$

dimana, $\mathrm{Cp}$ adalah koefisien daya, $\mathrm{P}_{\mathrm{mek}}$ adalah daya mekanik (W), $\mathrm{P}_{\mathrm{kin}}$ adalah daya kinetic (W)

d. TSR (Tip Speed Ratio), TSR adalah perbandingan antara kecepatan ujung blade dengan kecepatan angin bebas

$$
T S R=\frac{\pi D n}{60 v}
$$

Dimana, TSR adalah tip speed ratio, D adalah diameter sudu turbin (m), $\mathrm{n}$ adalah putaran turbin (rpm), $\mathrm{v}$ adalah kecepatan angin $(\mathrm{m} / \mathrm{s})$.

e. Daya Listrik, daya listrik adalah daya yang dihasilkan generator sehingga dapat juga disebut daya generator 
dimana, V adalah tegangan listrik (V), I adalah arus listrik (A).

Tahapan pekerjaan penelitian ditunjukkan pada Gambar 2 dibawah ini.

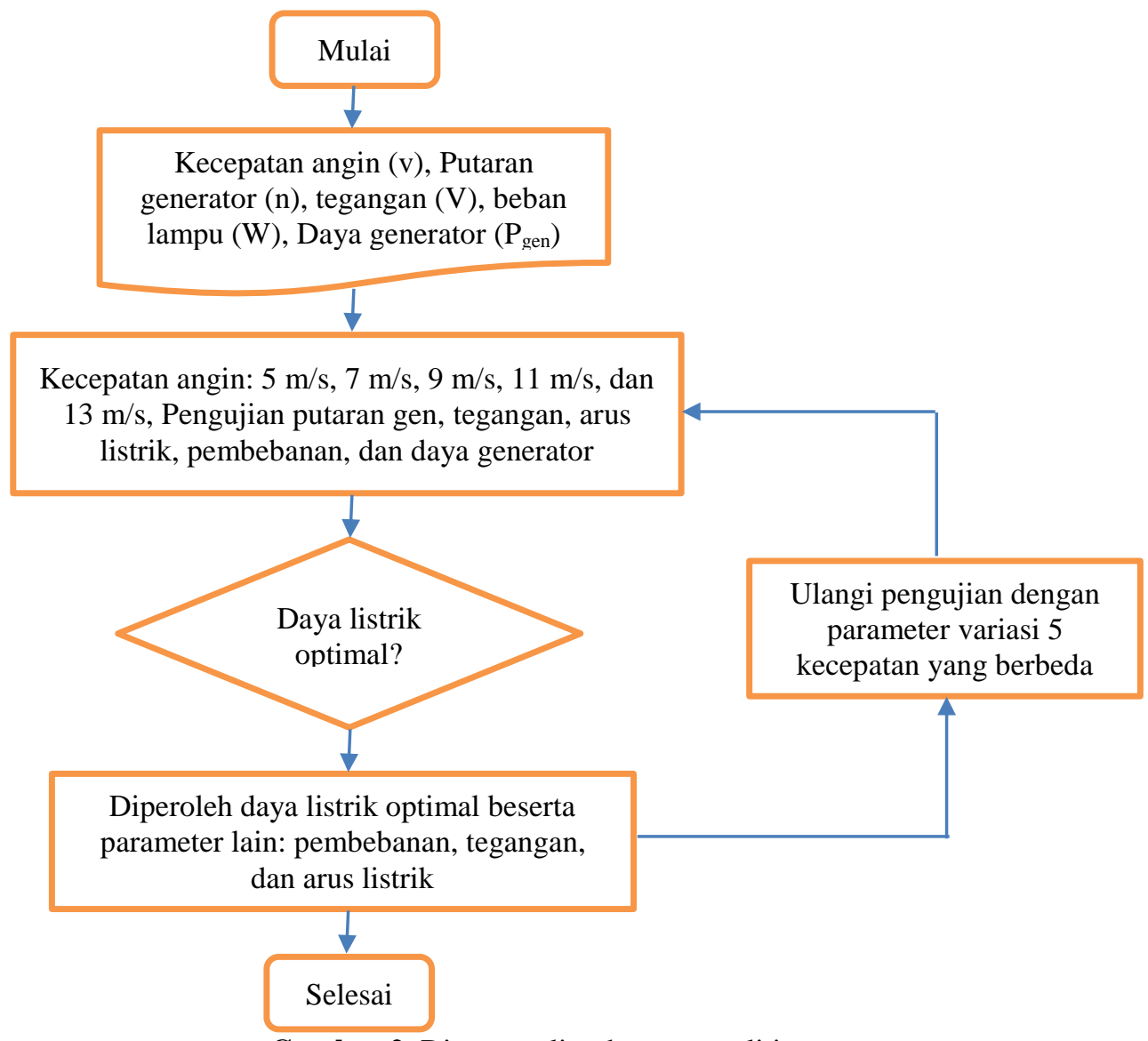

Gambar 2. Diagram alir tahapan penelitian

\section{Hasil dan pembahasan}

Data hasil pengujian diperoleh dari pengujian yang telah dilakukan di Laboratorium Teknik Konversi Energi Jurusan Teknik Mesin Politeknik Negeri Semarang. Blower merupakan alat yang digunakan untuk menghasilkan kecepatan angin. Data yang diambil adalah data yang dibutuhkan dalam menganalisa kinerja dari turbin angin. Data tersebut antara lain kecepatan angin (v), massa jenis udara ( $\rho)$, putaran generator (n), luas sapuan angin (A), tegangan (V), arus (I), dan nilai torsi.

Tabel 1. Pengujian turbin tanpa pembebanan dengan variasi kecepatan $5 \mathrm{~m} / \mathrm{s}, 7 \mathrm{~m} / \mathrm{s}, 9 \mathrm{~m} / \mathrm{s}, 11 \mathrm{~m} / \mathrm{s}, 13 \mathrm{~m} / \mathrm{s}$

\begin{tabular}{ccccccccc}
\hline \multirow{2}{*}{$\begin{array}{c}\text { Kecepatan } \\
\text { angin } \\
(\mathrm{m} / \mathrm{s})\end{array}$} & \multicolumn{2}{c}{ Single blade } & \multicolumn{2}{c}{ Double blade pada tip } & \multicolumn{2}{c}{ Double blade pada root } & \multicolumn{2}{c}{ Double blade } \\
\cline { 2 - 9 } & $\mathrm{rpm}$ & $\mathrm{V}_{\mathrm{dc}}$ & $\mathrm{rpm}$ & $\mathrm{V}_{\mathrm{dc}}$ & $\mathrm{rpm}$ & $\mathrm{V}_{\mathrm{dc}}$ & $\mathrm{rpm}$ & $\mathrm{V}_{\mathrm{dc}}$ \\
\hline 5 & 452 & 14,00 & 261 & 7,5 & 318 & 9 & 376 & 11 \\
7 & 540 & 17,00 & 489 & 14 & 442 & 13 & 424 & 11,4 \\
9 & 579 & 19,00 & 586 & 16 & 558 & 17 & 622 & 19 \\
11 & 733 & 23,00 & 631 & 19 & 493 & 15 & 718 & 22 \\
13 & 760 & 26,00 & 664 & 20 & 540 & 16 & 760 & 24 \\
\hline
\end{tabular}


Gambar 3 menunjukkan bahwa beban nol dapat dianalisa bahwa sudu single blade dengan kecepatan angin $5 \mathrm{~m} / \mathrm{s}$, $7 \mathrm{~m} / \mathrm{s}, 9 \mathrm{~m} / \mathrm{s}, 11 \mathrm{~m} / \mathrm{s}$ dan $13 \mathrm{~m} / \mathrm{s}$ menghasilkan putaran generator rata rata 612,8 rpm dan menghasilkan tegangan DC rata rata 19,8 V. Kemudian dapat dianalisa bahwa sudu double blade pada tip dengan kecepatan angin 5 m/s, 7 m/s, 9 m/s, 11 $\mathrm{m} / \mathrm{s}$ dan $13 \mathrm{~m} / \mathrm{s}$ menghasilkan putaran generator rata rata 526,2 rpm dan menghasilkan Vdc rata rata $11.5 \mathrm{~V}$. Kemudian dapat dianalisa bahwa sudu double blade pada root dengan kecepatan angin $5 \mathrm{~m} / \mathrm{s}, 7 \mathrm{~m} / \mathrm{s}, 9 \mathrm{~m} / \mathrm{s}, 11 \mathrm{~m} / \mathrm{s} \mathrm{dan} 13 \mathrm{~m} / \mathrm{s}$ menghasilkan putaran generator rata rata $470.2 \mathrm{rpm}$ dan menghasilkan tegangan DC rata rata $14 \mathrm{~V}$. Kemudian dapat dianalisa bahwa sudu double blade dengan kecepatan angin $5 \mathrm{~m} / \mathrm{s}, 7 \mathrm{~m} / \mathrm{s}, 9 \mathrm{~m} / \mathrm{s}, 11 \mathrm{~m} / \mathrm{s}$ dan $13 \mathrm{~m} / \mathrm{s}$ menghasilkan putaran generator rata rata $580 \mathrm{rpm}$ dan menghasilkan tegangan DC rata rata $17.48 \mathrm{~V}$. Dari beberapa jenis turbin, jenis single blade memiliki putaran dan tegangan tertinggi dibandingkan jenis turbin lainnya, karena sudu single blade mempunyai berat lebih ringan dari pada jenis sudu yang lain.

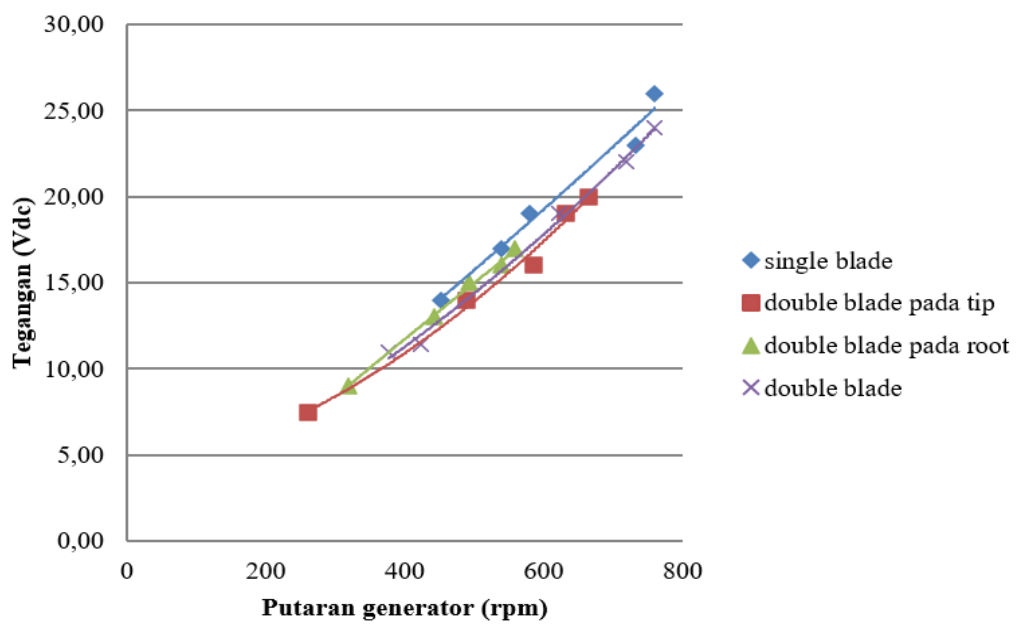

Gambar 3. Unjuk kerja turbin Savonius tanpa pembebanan

Tabel 2. Daya generator rata rata pada kecepatan $5 \mathrm{~m} / \mathrm{s}, 7 \mathrm{~m} / \mathrm{s}, 9 \mathrm{~m} / \mathrm{s}, 11 \mathrm{~m} / \mathrm{s}$, dan $13 \mathrm{~m} / \mathrm{s}$

\begin{tabular}{ccccc}
\hline Beban lampu (W) & Single blade & $\begin{array}{c}\text { Sudu 1/4 } \\
\text { lingkar luar }\end{array}$ & $\begin{array}{c}\text { Sudu 1/4 } \\
\text { lingkar dalam }\end{array}$ & Double blade \\
\hline 0 & 0 & 0 & 0 & 0 \\
5 & 5.29 & 3.61 & 3.23 & 4.64 \\
10 & 5.51 & 3.92 & 3.68 & 5.56 \\
15 & 6.03 & 3.64 & 3.40 & 5.20 \\
20 & 6.08 & 4.30 & 3.72 & 6.05 \\
25 & 5.06 & 3.86 & 3.31 & 5.50 \\
30 & 4.53 & 3.35 & 2.93 & 4.77 \\
35 & 3.71 & 2.85 & 2.31 & 4.22 \\
\hline
\end{tabular}

Gambar 4 menjelaskan bahwa pengaruh beban terhadap daya listrik dapat dianalisa sudu single blade dengan kecepatan angin rata rata $5 \mathrm{~m} / \mathrm{s}, 7 \mathrm{~m} / \mathrm{s}, 9 \mathrm{~m} / \mathrm{s}, 11 \mathrm{~m} / \mathrm{s}$ dan $13 \mathrm{~m} / \mathrm{s}$ menghasilkan daya listrik $5.29 \mathrm{~W}$ dengan beban lampu 5 W. Kemudian dapat dianalisa sudu 1/4 lingkaran luar dengan kecepatan angin rata rata 5, 7, 9, 11 dan 13 m/s menghasilkan daya listrik 3.61 W dengan beban lampu 5 W. Kemudian dapat dianalisa sudu 1/4 lingkaran dalam dengan kecepatan angin rata rata $5 \mathrm{~m} / \mathrm{s}, 7 \mathrm{~m} / \mathrm{s}, 9 \mathrm{~m} / \mathrm{s}, 11 \mathrm{~m} / \mathrm{s}$, dan $13 \mathrm{~m} / \mathrm{s}$ menghasilkan daya listrik $3.23 \mathrm{~W}$ dengan beban lampu 5 W. Kemudian dapat dianalisa sudu double blade dengan kecepatan angin rata rata $5 \mathrm{~m} / \mathrm{s}, 7 \mathrm{~m} / \mathrm{s}, 9 \mathrm{~m} / \mathrm{s}, 11 \mathrm{~m} / \mathrm{s} \mathrm{dan} 13$ $\mathrm{m} / \mathrm{s}$ menghasilkan daya listrik $4.64 \mathrm{~W}$ dengan beban lampu $5 \mathrm{~W}$. Dari beberapa jenis turbin, jenis single blade 
menghasilkan putaran tercepat dibandingkan jenis turbin lainnya, karena sudu single blade mempunyai berat lebih ringan dari pada jenis sudu yang lain yang mengakibatkan turbin tidak terlalu berat dalam berputar.

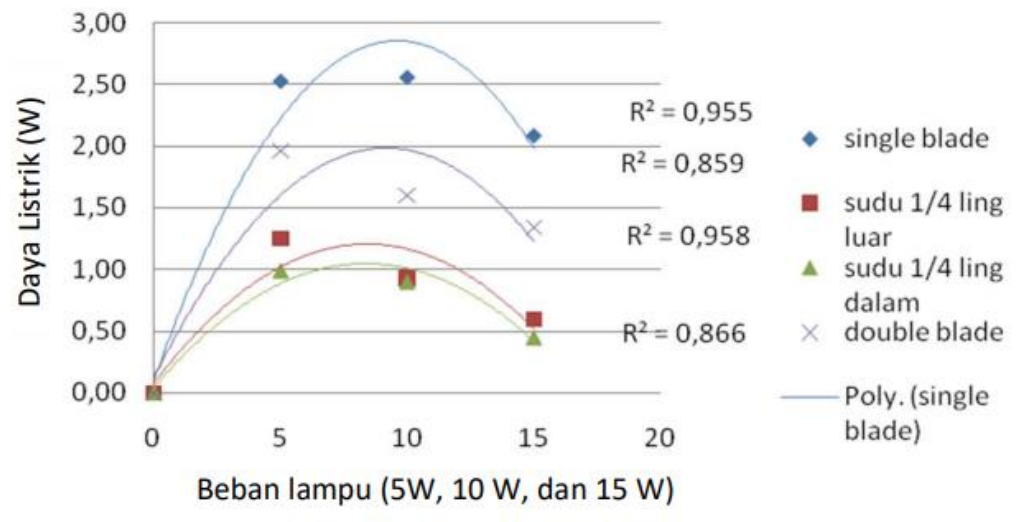

Gambar 4. Unjuk kerja daya listrik terhadap pembebanan (5 W, $10 \mathrm{~W}$, dan $15 \mathrm{~W})$

Keunggulan teknologi turbin Savonius model ini adalah: 1) sisi keunggulan inovatif merupakan pendekatan teknologi menggunakan turbin Savonius skala laboratorium dan penerapan untuk pembangkit tenaga listrik off-grid untuk menghasilkan daya sesuai kebutuhan; 2) sisi keunggulan komparatif bahwa turbin Savonius ini dapat menerima energi angin dari segala arah dan bisa meningkatkan efisiensi dan material yang murah, mudah diduplikasi, dan mudah didapatkan di pasaran akan menekan biaya produksi. Sehingga memiliki prospek aplikasi yang luas dalam penerapan sudu Savonius meningkatkan gaya dorong sehingga menghasilkan torsi yang lebih besar, dukungan material yang murah dan mudah diperoleh dipasaran, akan menekan biaya investasi, serta desain turbin untuk kecepatan angin rendah bisa diaplikasikan di seluruh wilayah Indonesia yang memiliki potensi angin rata-rata 3-5 m/s.

\section{Kesimpulan}

Penelitian turbin angin Savonius putaran rendah menggunakan generator sinkron magnet permanen ini memiliki spesifikasi sebagai berikut: rangka sudu tingginya $700 \mathrm{~mm}$ dan dimensi sudu turbin tinggi $800 \mathrm{~mm}$, lebar diameter sudu $680 \mathrm{~mm}$. Mekanisme transmisi menggunakan v-belt dan pulley berdiameter $60 \mathrm{~mm}$ dan $120 \mathrm{~mm}$ yang dihubungkan dengan generator AC sinkron magnet permanen. Turbin Savonius tanpa pembebanan sudu single blade dengan kecepatan angin $5 \mathrm{~m} / \mathrm{s}, 7 \mathrm{~m} / \mathrm{s}, 9 \mathrm{~m} / \mathrm{s}, 11 \mathrm{~m} / \mathrm{s}$ dan $13 \mathrm{~m} / \mathrm{s}$ menghasilkan putaran generator rata rata $612,8 \mathrm{rpm}$ dan menghasilkan tegangan DC rata rata 19,8 V. Turbin Savonius pada sudu single blade dengan kecepatan angin rata rata $5 \mathrm{~m} / \mathrm{s}, 7 \mathrm{~m} / \mathrm{s}, 9$ $\mathrm{m} / \mathrm{s}, 11 \mathrm{~m} / \mathrm{s}$ dan $13 \mathrm{~m} / \mathrm{s}$ menghasilkan daya listrik $5.29 \mathrm{~W}$ dengan beban lampu $5 \mathrm{~W}$.

\section{Ucapan Terima kasih}

Peneliti mengucapkan terima kasih kepada Kementerian Pendidikan, Kebudayaan, Riset, dan Teknologi atas dukungan pendanaan Penelitian Desentralisasi tahun 2021 dengan nomor kontrak: 259/E4.1/AK.04.PT/2021 pada skim Penelitian Terapan Unggulan Perguruan Tinggi (PTUPT) Politeknik Negeri Semarang.

\section{Daftar Pustaka}

[1] Akwa, J. V., Vielmo, H. A., Petry, A. P., A review on the performance of savonius wind turbin. Renewable and Sustainable Energi Reviews. 2012; 16: p. 3054-3064. 
[2] Herlambang, Y.D., Supriyo, S., Prasetiyo, B., Improved Savonius double blade performance using modified blade shaped with variations of the wind flow ratios on the blade inlet and outlet side. IOP Conf. Series: Materials Science and Engineering, Proceeding of International Conference on Innovation in Science and Technology (ICIST); 17-18 Desember 2019; Indonesia, IOP Publishing; 1108 (1). p 012041.

[3] Herlambang, Y.D., Supriyo, S., Prasetiyo, B., Wahyono, W., dan Mulud, T.H., Model turbin angin airfoil NACA 4418 terhadap variasi bukaan sudut sudu pada kecepatan angin berbeda. Jurnal Integrasi. 2019 Oktober; 11 (2): p. 97-102.

[4] Ali, M.H., Eksperimental comparison study for Savonius wind turbine of two and three blades at low wind speed. International Journal of Modern Research (IJMER). 2013; 3 (5): p. 2978-2986.

[5] Herlambang, Y.D., Surindra, M.D., Safarudin, Y.M., Pembuatan turbin double Spherical sebagai upaya memperbaiki kinerja turbin Spherical. Eksergi Jurnal Teknik Energi. 2018 September; 14 (3): p. 59-65.

[6] Herlambang, Y.D., Margana, M., Safarudin, Y.M., Yosintaska, Y., Yusarindra, N., Wibowo, R.R., Cahya, Y.T.I., Model alat ukur kecepatan angina rah angin dan intensitas radiasi matahari. Eksergi Jurnal Teknik Energi. 2020 Mei: 16 (2): p. 80-91.

[7] Herlambang, Y.D., Hendrawati, D., Agustin, A.D., Kusuma, K.A., Wahyuningsih, S., Wigiantoro, W., Model turbin angin Savonius untuk meningkatkan kinerja PLTB. Eksergi Jurnal Teknik Energi. 2020 Januari; 16 (1): p. 35-39.

[8] Asy'ari, H., Jatmiko, Ardiyatmoko, A., Desain Generator Magnet Permanen Kecepatan Rendah Untuk Pembangkit Listrik Tenaga Angin Atau Bayu (PLTB). Seminar Nasional Aplikasi Teknologi Informasi. 2012. ISSN: 1907-5022

[9] Damak, A., Driss, Z., Abid, M.S., Experimental investigation of helical savonius rotor with a twist of $180^{\circ}$. Renewable Energy. 2013. 52: p. 136-142.

[10] Herlambang, Y.D., Wahyono, W., Rancang bangun turbin angin poros horizontal 9 sudu flat dengan variasi rasio lebar sudu top dan bottom untuk meningkatkan kinerja turbin. Eksergi Jurnal Teknik Energi. 2019 Mei; 15 (2): p. 70-76.

[11] Wenehenubun, F., Saputra, A., Sutanto, H. An Experimental study on the performance of savonius wind turbines related with the number of blades. Energi Procedia. 2015; 68: p. 297-304.

[12] Hau, E., Wind turbines: fundamentals, technologies, application, economics. $2^{\text {nd }}$ edition. New York: SpringerVerlag Berlin Heidelberg; 2006. p. 81-86.

[13] Latif, M. Efisiensi prototipe turbin Savonius pada kecepatan angin rendah. Jurnal Rekayasa Elektrika. 2013; 10: p. $147-151$

[14] Herlambang, Y. D. \& Suwarti, (2013). Model Turbin Savonius 1-Tingkat Sebagai Penggerak Mula Pompa Air tanpa Bahan Bakar untuk Pengairan. Eksergi Jurnal Teknik Energi. 9 (1): 18-23.

[15] Herlambang, Y.D., Hendrawati, D., Sudjito, S., Turbin angin vertical sudu aerofoil NACA 0018 series berbasis konstruksi helical/twist terhadap variasi sudut sudu. Eksergi Jurnal Teknik Energi. 2017 September; 13 (3): p. 92 101.

[16] Herlambang, Y.D., Suwarti, S., Model turbin Savonius 1-tingkat sebagai penggerak mula pompa air tanpa bahan bakar untuk pengairan. Eksergi Jurnal Teknik Energi. 2013 Januari; 9 (1): p. 18-23. 